\title{
Cigarette smoking extract causes hypermethylation and inactivation of WWOX gene in T-24 human bladder cancer cells
}

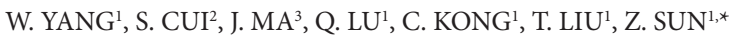 \\ ${ }^{1}$ Department of Urology; ${ }^{2}$ Department of Thoracic Surgery, The First Affiliated Hospital of China Medical University, Shenyang 110001, People's \\ Republic of China; ${ }^{3}$ Department of Nursing, Hebei University of Engineering, Handan 056029, People's Republic of China
}

${ }^{*}$ Correspondence: $z h x \_s u n @ 163 . c o m$

Received September 19, 2011 / Accepted October 12, 2011

\begin{abstract}
Genomic, epigenetic and expression alterations of WW domain containing oxidoreductase (WWOX) have been implicated in multiple tumor types. The current study was designed to examine the expression of WWOX in tumor tissues of human bladder transitional cell carcinoma (BTCC) and the influence of cigarette smoke extract (CSE) on WWOX expression and methylation status in T-24 bladder cancer cells. WWOX protein expression was evaluated by immunohistochemistry staining in a series of tumor samples from 78 patients with BTCC and 26 normal bladder tissues. The expression level and methylation status of WWOX in CSE-treated cells were examined by using quantitative Real-Time RT-PCR and methylation specific PCR, respectively. The expression levels of DNA methyltransferases (DNMTs) 1, 3A and 3B were also detected. We found that WWOX expression was absent or reduced in 79.5\% (62/78) of BTCC tissues, but only in 19.2\% (5/26) of normal bladder tissues. Loss of WWOX expression was correlated with tumor grade $(P=0.019)$ and cigarette smoking $(P=0.031)$, but was not associated with age, gender, tumor size and tumor number. Hypermethylation of WWOX promoter and exon 1 was specifically induced by CSE with a kinetics concurrent to the suppression of WWOX mRNA in T-24 cells. Furthermore, CSE treatment induced a significant time-dependent increase in the level of DNMT1, but has no effects on DNMT3A and DNMT3B. Taken together, these novel findings suggest that hypermethylation of WWOX induced by cigarette smoking may represent one underlying mechanism for the loss expression of WWOX in bladder cancer.
\end{abstract}

Key words: WWOX, bladder cancer, immunohistochemistry, cigarette smoking, DNA methylation

Bladder cancer is one of the most prevalent cancers, with an estimated of 386,300 new cases and 150,200 deaths in 2008 worldwide (1). Transitional cell carcinoma comprises about $90 \%$ of all urinary bladder cancers and is the second most frequent malignancy of the genitourinary tract (2). Environmental and/or occupational factors have been proposed to be involved in different cancer types including bladder cancer (3). Specifically, cigarette smoking has long been known as a major risk factor for bladder cancer $(4,5)$. However, the mechanism by which cigarette smoking contributes to bladder carcinogenesis remains unknown. Therefore, the etiology of cigarette smoking in carcinogenesis has become specific interests among oncologists and scientists.

Carcinogenesis is a complex multiple process that is accompanied by frequent genetic alterations including chromosomal translocations, inversions, deletions, and amplifications. In particular, two most common fragile regions within human genome, located at the short arm of chromosome 3 (3p) and the long arm of chromosome $16(16 \mathrm{q})$, are frequent targets of homozygous deletion and loss of heterozygosity (LOH) in various epithelial tumors, such as breast, prostate, stomach, and bladder (6-9). Two tumor suppressor genes FHIT (fragile histidine triad) and WWOX (WW domain containing oxidoreductase) have been mapped to chromosome $3 \mathrm{p}$ and $16 \mathrm{q}$, respectively. FHIT gene lies on a region of over $1 \mathrm{Mb}$ of chromosome 3p14.2 that contains the FRA3B fragile region and encodes a protein of 147 amino acids (16.8 KDa) with diadenosine triphosphate hydrolase activity (10). WWOX gene, also known as WOX1 or FOR II, spans the second most common fragile site region FRA16D. WWOX is a very large gene spanning $1.11 \mathrm{Mb}$ consisting of nine small exons separated by large introns. It encodes a $46 \mathrm{KDa}, 414$-amino acid protein containing two $\mathrm{N}$ terminal WW domains and a short-chain dehydrogenase/reductase (SDR) central domain (11). 
In the last decade, numerous studies have demonstrated that FHIT and WWOX are altered at the genomic, epigenetic and expression levels in many tumor types $(12,13)$. Reports have also been shown that exposure to environmental carcinogens such as smoking, increases the chromosome breakage at fragile sites FRA3B and FRA16D in some types of epithelial tumors $(14,15)$. Remarkably, it is well established that FHIT gene alterations are correlated with cigarette smoking in lung cancer (16). As another representative cancer-related fragile site gene, little is known about, whether WWOX gene expression is associated with cigarette smoking in bladder cancer. Therefore, we employed immunohistochemistry staining to examine the WWOX protein expression in a series of tumor samples from 78 patients with bladder transitional cell carcinoma (BTCC) and 26 normal bladder tissues. Then the relations of WWOX expression and clinical features were analyzed. Moreover, because cigarette smoking has been demonstrated to induce epigenetic changes through promoter methylation of tumor suppressor genes, we sought to investigate whether similar mechanism of WWOX occurs also in bladder cancer cells (17-19). To this end, we treated bladder cancer T-24 cells with cigarette smoke extract (CSE) and further examined the expression level of WWOX and DNA methyltransferases (DNMTs) as well as the methylation status of $\mathrm{CpG}$ islands within the WWOX promoter and exon 1.

\section{Materials and Methods}

Patients and specimens. A total of 78 patients diagnosed with BTCC and 26 patients with normal bladder tissues were enrolled in the study. Normal urothelial mucosae were obtained from non-BTCC patients who had undergone partial cystectomy or cystoprostatectomy for bladder diverticulum or large benign prostatic hyperplasia. The BTCC patients consisted of 59 men and 19 women. The ages of these patients ranged from 28 to 84 years, with a mean age of 50.9 years. According to the 2004 World Health Organization (WHO) guidelines, $26.9 \%$ (21/78) tumors were classified as Grade 1, 42.3\% (33/78) Grade 2, and 30.8\% (24/78) Grade 3. Patients with a history of urinary infection, prostatic carcinoma or tuberculosis of bladder were excluded. None of these cases underwent either chemotherapy or radiotherapy before surgery. Study participants underwent a complete transurethral resection or radical cystectomy of bladder tumor at the First Affiliated Hospital of China Medical University in Shenyang, and all of them gave informed consent for the use of tumor tissue specimens for clinical research. All tissues were fixed in $10 \%$ buffered formalin and paraffin embedded. All patients underwent a personal interview to obtain information including cigarette usage (such as duration, frequency and intensity of cigarette smoking), and classified as variable comparing never, former and current smokers. Former smokers were defined as those who had quit smoking $>12$ months before tumor diagnosis (20). The extent of smoking was classified by Brinkman index $(\mathrm{BI}=$ filter-tipped cigarettes per day $\times$ years smoked $)$ : heavy, $\mathrm{BI} \geq 3000$; moderate, $900 \leq \mathrm{BI}<3000$; and light, $\mathrm{BI}<900$, according to the median number of filter-tipped cigarettes per year (21). Bladder tumors were reviewed by the experienced pathologist and classified according to the 2004 World Health Organization (WHO) guidelines for bladder tumors.

Immunohistochemical staining. Tissue sections from bladder tumor and normal mucosas were stained with WWOX antiserum. The details of immunostaining methods were described previously (22). Negative controls were set in each experiment. Immunohistochemical staining of paraffin-embedded slides was performed using the avidin-biotin complex technique. For each case, a single representative slide was selected for staining and histologic evaluation. Briefly, slides were dewaxed in xylene and hydrated with graded ethanol. Slides underwent antigen retrieval in Citra solution using the Biocare Decloaking Chamber (Biocare Medical, Walnut Creek, CA, USA). Staining of WWOX was performed using a polyclonal antibody (BioGenex, San Ramon, CA, USA) at a 1: 100 dilution. An appropriate positive control was used in each staining run, and each slide was stained with a negative control. Two experienced pathologists independently examined multiple fields and scored tissue sections for extent of staining. Immunostaining was expressed as the percentage of stained cells out of total number of tumor cells, and assigned to one of five categories: $0,<5 \% ; 1,5 \% \sim 25 \% ; 2,25 \% \sim 50 \%$; $3,50 \% \sim 75 \%$, and $4,>75 \%$. The intensity of immunostaining was graded on a semi-quantitative scale (0-3): 0 , absent; 1 , weak; 2 , moderate; 3 , intense. The two scores were multiplied and the product was defined as immunohistochemical score. According to the immunohistochemical scores, WWOX expression was then finally divided into two groups: low-level WWOX expression (with a score $\leq 2$ ), and high-level WWOX expression (with a score $\geq 3$ ).

Cell culture and treatment. Human bladder cancer cells T-24, obtained from the Cell Bank of Type Culture Collection of Chinese Academy of Sciences (Shanghai, China), were maintained in McCoy medium (Gibco, Grand Island, NY, USA) supplemented with $10 \%$ newborn bovine serum (NBS, Sijiqing Biological Engineering Materials Co., Ltd., Hangzhou, China), penicillin $(100 \mathrm{U} / \mathrm{mL})$ and streptomycin $(100 \mathrm{mg} / \mathrm{mL})$. Cells were incubated with $1 \mathrm{~mL}$ of medium at $37^{\circ} \mathrm{C}$ in a tissue culture incubator equilibrated with $95 \%$ air and $5 \% \mathrm{CO}_{2}$. Cigarette smoke extract (CSE) was prepared by using commercial cigarettes with filter as previously described by Oltmanns et al. (23). At near confluence, the cells were exposed to varying concentrations of CSE dissolved in medium for different intervals.

Methylation-specific PCR. Genomic DNA was extracted from CSE treated cells by using the TIANamp Genomic DNA Kit (Tiangen Biotech Co., Ltd., Beijing, China) according to the manufacturer's instructions. Then, $1 \mu \mathrm{g}$ genomic DNA was modified by sodium bisulfite with the CpGenome ${ }^{\mathrm{TM}}$ DNA Modification Kit (Chemicon, Billerica, MA, USA). MSP was performed using the primer sequences for methylated and unmethylated WWOX promoter and exon 1 DNA as reported previously (24). CpGenome ${ }^{\mathrm{TM}}$ universal unmethylated DNA 

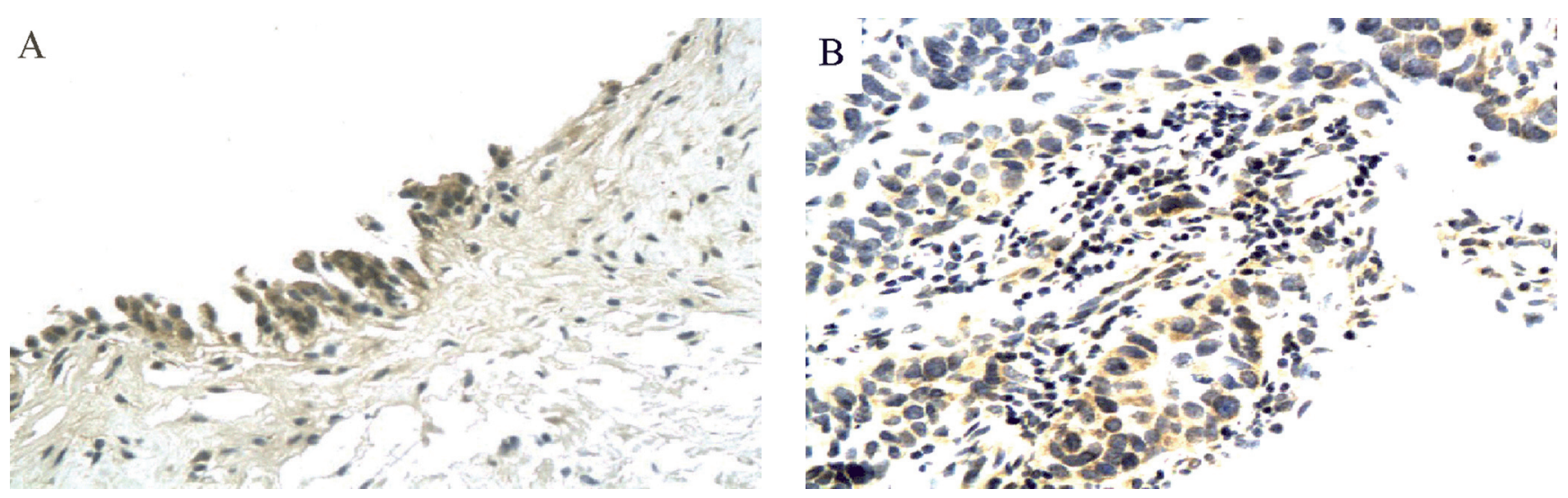

Figure 1. Immunohistochemical detection of WWOX protein in normal bladder tissue and bladder transitional cell carcinoma (BTCC) (A) Normal bladder specimen with strong expression of WWOX protein; (B) BTCC tissue sample with weak WWOX staining.

and methylated DNA were purchased from Chemicon and served as controls for MSP analysis.

Quantitative Real-Time RT-PCR. Total RNA from CSE treated cells was isolated using the RNAsimple total RNA kit (Tiangen, Beijing, China) according to the manufacturer's instructions. $1 \mu \mathrm{g}$ total RNA was reverse transcribed using the TIANScript RT Kit (Tiangen). Quantitative Real-Time RTPCR was performed using SYBR green (Tiangen) on Exicycler ${ }^{\mathrm{rm}}$ 96 Real-Time Quantitative Thermal Block (Bioneer, Daejeon, Korea). The PCR primer sequences are shown in Table 1. The specificity of the PCR was confirmed by examining the dissociation reaction plot subsequent to Real-Time RT-PCR. $\beta$ actin served as the constitutive control. PCR reactions of each sample were done in triplicate. Data were analyzed through the comparative threshold cycle $\left(\mathrm{C}_{\mathrm{T}}\right)$ method.

Western blot analysis. Cells treated with CSE were lysed in RIPA buffer and protein concentrations were determined by using a bovine serum albumin (BSA) standard line. Equal amounts of protein were separated by SDS-PAGE and then electrotransferred to PVDF membranes (Millipore, Bedford, MA, USA). Membranes were blocked with 5\% skim milk, incubated overnight $\left(4^{\circ} \mathrm{C}\right)$ with anti-DNMT1 (Imgenex, San Diego, CA, USA) or anti- $\beta$-actin (Sigma-Aldrich, Saint Louis, MO, USA) antibodies, followed by horseradish peroxidase-conjugated secondary antibodies. Protein bands were visualized with ECL plus chemiluminescence kit (Millipore, Bedford, MA, USA).

Statistical analysis. Data were expressed as mean \pm standard deviation (SD), or median and range as appropriate. Data were analyzed by the chi-square test, unpaired Student's $t$ test or ANOVA using GraphPad Prism 5.0 (GraphPad Software Inc., La Jolla, CA, USA). A P-value of less than 0.05 was considered statistically significant.

\section{Results}

Immunohistochemistry staining of WWOX protein expression in bladder tissues. Of 26 normal bladder specimens, cytoplasmic staining for WWOX protein was present in $80.9 \%(21 / 26)$ and served as internal positive controls. The intensity of the staining in the normal appearing epithelium could be classified as moderate to strong (Figure

Table 1. Primer sequences used for quantitative Real-Time RT-PCR

\begin{tabular}{|c|c|c|c|}
\hline Primer & Sequences & Annealing temperature $\left({ }^{\circ} \mathrm{C}\right)$ & Product size (bp) \\
\hline WWOX-F & 5'-GAGAGGCTGATCCAAGAACG-3' & \multirow{2}{*}{62} & \multirow{2}{*}{152} \\
\hline WWOX-R & 5’-ACTCTTGCGGATCTGTGTTG-3’ & & \\
\hline DNMT1-F & 5'-GGTTCTTCCTCCTGGAGAATGTC-3' & \multirow{2}{*}{58} & \multirow{2}{*}{141} \\
\hline DNMT1-R & 5'-GGGCCACGCCGTACTG-3' & & \\
\hline DNMT3A-F & 5'-GCCTCAATGTTACCCTGGAA-3' & \multirow{2}{*}{60} & \multirow{2}{*}{127} \\
\hline DNMT3A-R & 5'-CAGCAGATGGTGCAGTAGGA-3' & & \\
\hline DNMT3B-F & 5'-CCCATTCGAGTCCTGTCATT-3' & \multirow{2}{*}{60} & \multirow{2}{*}{126} \\
\hline DNMT3B-R & 5'-GGTTCCAACAGCAATGGACT-3' & & \\
\hline$\beta$-actin-F & 5'-GAAATCGTGCGTGACATTAA-3' & \multirow{2}{*}{60} & \multirow{2}{*}{179} \\
\hline$\beta$-actin-R & 5'AAGGAAGGCTGGAAGAGTG-3' & & \\
\hline
\end{tabular}

Abbreviations: WWOX, WW domain containing oxidoreductase; DNMT, DNA methyltransferase 
A

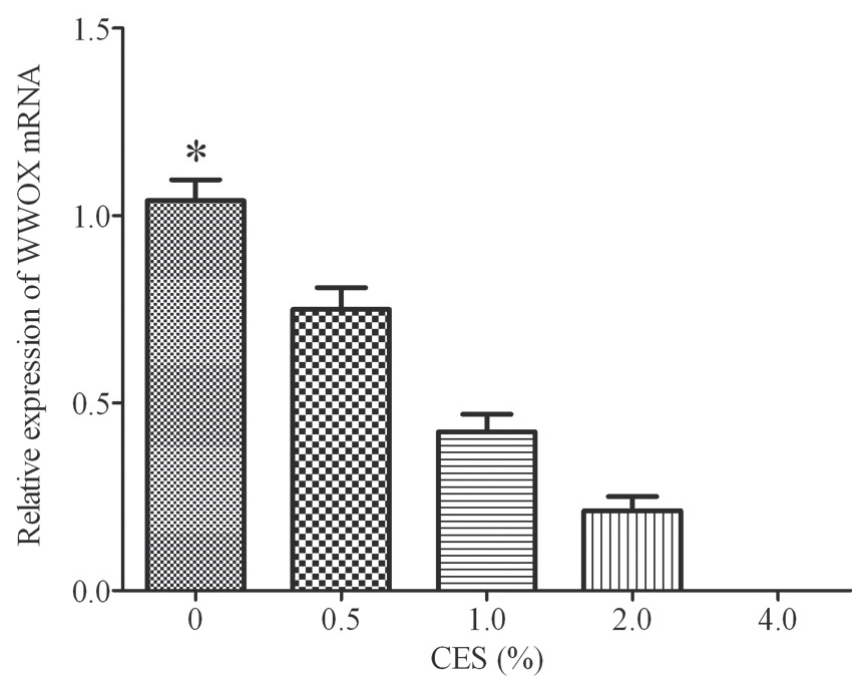

$\mathrm{C}$

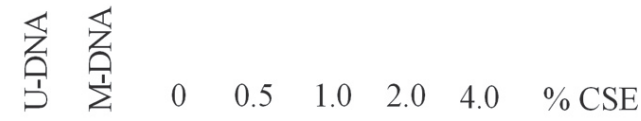

WWOX-P-M

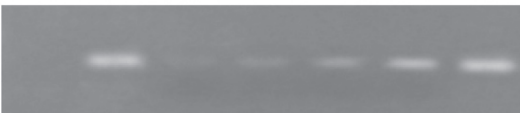

347 bp

WWOX-P-U

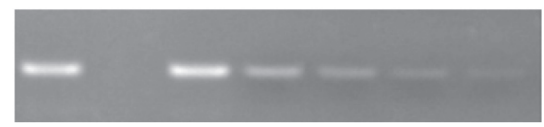

$347 \mathrm{bp}$

E

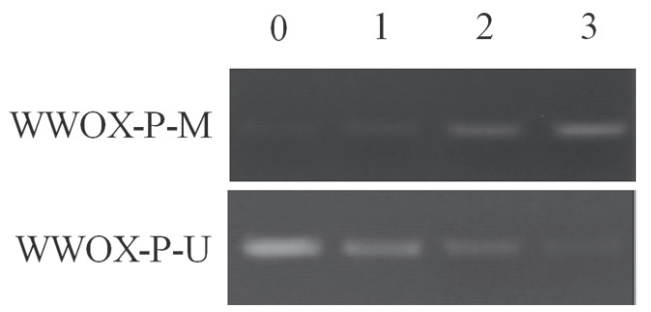

CSE (day)

347 bp

347 bp

B

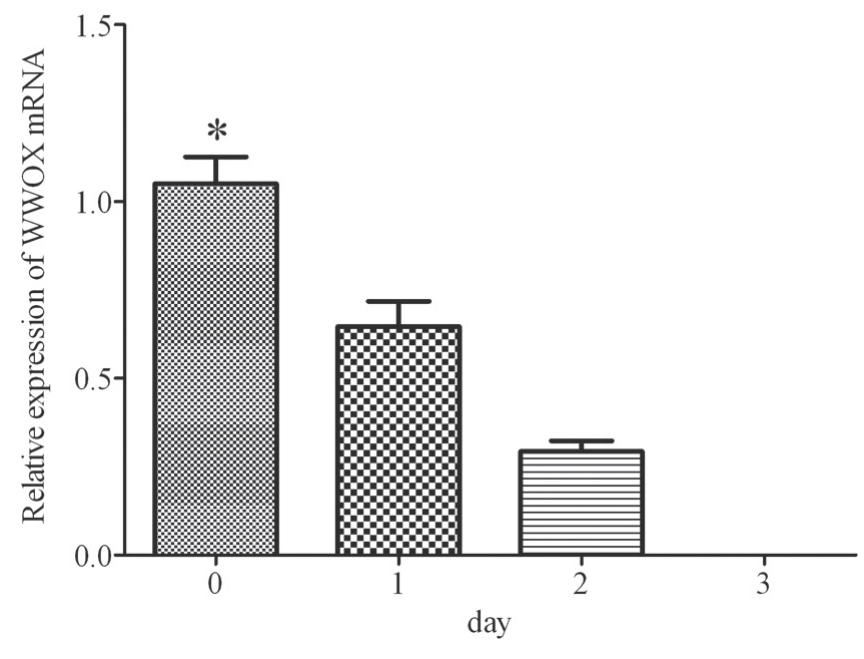

$\mathrm{D}$

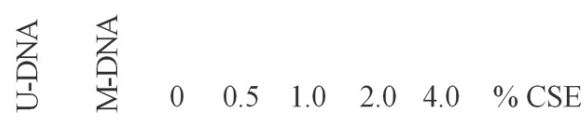

WWOX-exon 1-M

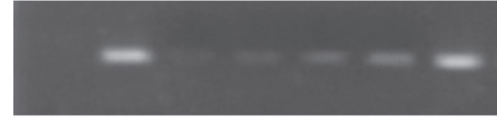

$91 \mathrm{bp}$

WWOX-exon 1-U

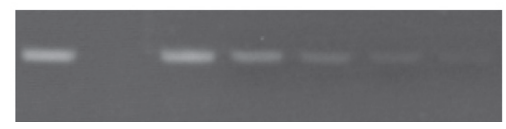

$91 \mathrm{bp}$

$\mathrm{F}$

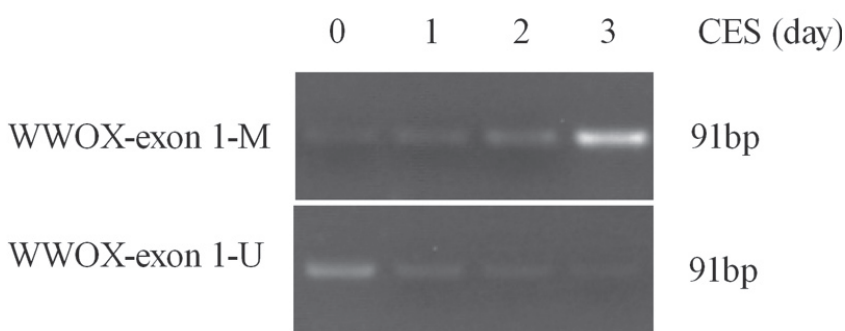

Figure 2. CSE treatment induced suppression and hypermethylation of WWOX gene in a dose- and time-dependent manner in T-24 cells. T-24 cells were treated with varying concentrations of CSE for 3 days or $4 \%$ CSE for different intervals. Dose-dependent effects of CSE on the expression of WWOX mRNA (A), methylation status of WWOX promoter (C) and exon 1 (D). Time-dependent effects of CSE on the expression of WWOX mRNA (B), methylation status of WWOX promoter (E) and exon 1 (F). U-DNA, universal unmethylated DNA; M-DNA, universal methylated DNA. * indicate $P$ values less than 0.05 .

1A). Among the tumor samples, WWOX staining was heterogeneous, displaying diffusely negative or rare positive scattered cells to diffusely positive or a mixed pattern of both weak and strong staining, suggesting that phenotypic heterogeneity is a major feature in bladder cancer (Figure 1B). According to the above scoring criteria, low-level of WWOX protein expression was observed in 62 out of 78
(79.5\%) and high expression in 16 out of 78 (20.5\%). Table 2 shows the relations of WWOX and clinicopathological factors. Remarkably, there was a strong association between the loss of WWOX expression and tumor grade $(P=0.019)$ as well as cigarette smoking ( $P=0.031)$ (Table 2 and 3$)$. The frequency of WWOX expression did not differ significantly in different age or gender groups. 
CSE inhibited WWOX expression in T-24 bladder cancer cells through the induction of CpG islands methylation. Considering the fact that there was a strong association between the loss of WWOX expression and cigarette smoking in patients with bladder cancer, we investigated the effects of CSE on WWOX mRNA expression in human bladder cancer cells T-24. CSE was added to culture medium of T-24 cells at various final concentrations for 3 days. During the treatment, medium was changed daily with fresh CSE. At the end of treatment, treated and control cells were harvested for RNA and DNA isolation. Quantitative Real-Time RT-PCR revealed that CSE treatment inhibited the expression of WWOX in a dose- and time-dependent fashion (Figure 2A and B). Notably, a completely inhibition was achieved after treatment with $4 \%$ CSE for 3 days.

Previous studies have demonstrated that CSE could induce epigenetic alterations through promoter methylation of tumor suppressor genes. In order to explore the underlying molecular mechanisms by which CSE causes the inhibition of

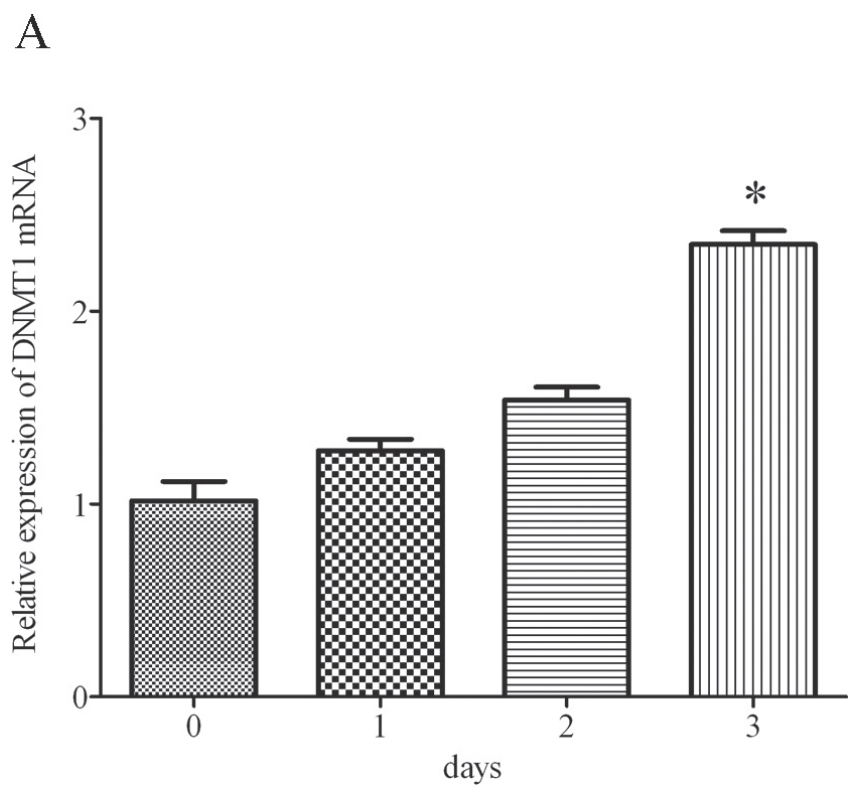

B

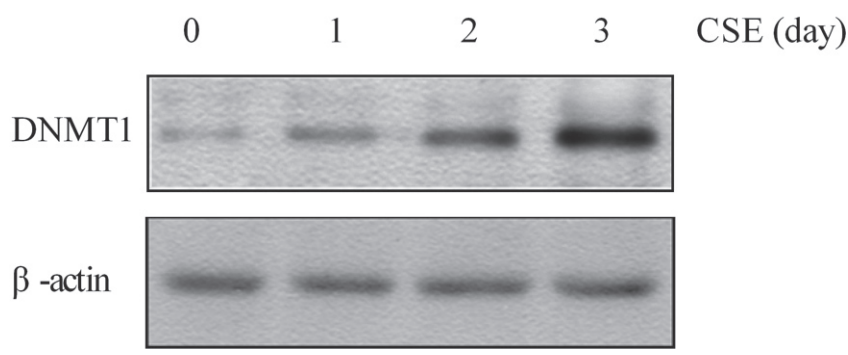

Figure 3 Elevated expression of DNMT1 was induced by CSE in T-24 cells. (A) Analysis of DNMT1 expression by quantitative Real-Time RT-PCR. (B) Analysis of DNMT1 expression by western blot. ${ }^{*}$ indicates $P$ value less than 0.05 .
WWOX expression in T-24 cells, we employed MSP analysis to examine the methylation status of $\mathrm{CpG}$ islands within the WWOX promoter and exon 1 in 4\% CSE treated and untreated cells. As shown in Figure 2C and D, a significant amount of WWOX methylated promoter was observed after 1 day of treatment and the promoter became near fully methylated after a 3-day exposure. In addition, the methylation of WWOX exon 1 induced by CSE displayed almost identical

Table 2. Correlations of WWOX expression and clinicopathologic characteristics in BTCC

\begin{tabular}{|c|c|c|c|c|}
\hline \multirow{2}{*}{ Groups } & \multirow{2}{*}{ Samples (n) } & \multicolumn{2}{|c|}{ WWOX protein expression } & \multirow{2}{*}{$P$ value } \\
\hline & & Low & High & \\
\hline Normal mucosa & 26 & 5 & 21 & 2.7E-08 \\
\hline BTCC & 78 & 62 & 16 & \multirow{4}{*}{0.947} \\
\hline \multicolumn{4}{|l|}{ Gender } & \\
\hline Male & 59 & 47 & 12 & \\
\hline Female & 19 & 15 & 4 & \\
\hline \multicolumn{4}{|l|}{ Age (years) } & \multirow{3}{*}{0.664} \\
\hline$<50$ & 28 & 23 & 5 & \\
\hline$\geq 50$ & 50 & 39 & 11 & \\
\hline \multicolumn{4}{|l|}{ Tumor size $(\mathrm{cm})$} & \multirow{3}{*}{0.258} \\
\hline$<1$ & 49 & 37 & 12 & \\
\hline$\geq 1$ & 29 & 25 & 4 & \\
\hline \multicolumn{4}{|l|}{ Tumor numbers } & \multirow{3}{*}{0.285} \\
\hline$\leq 2$ & 21 & 15 & 6 & \\
\hline$>2$ & 57 & 47 & 10 & \\
\hline \multicolumn{4}{|l|}{ Onset } & \multirow{3}{*}{0.321} \\
\hline Recurrent & 26 & 19 & 7 & \\
\hline Non-recurrent & 52 & 43 & 9 & \\
\hline \multicolumn{4}{|l|}{ Pathology grade } & \multirow{4}{*}{0.019} \\
\hline I & 21 & 13 & 8 & \\
\hline II & 33 & 26 & 7 & \\
\hline III & 24 & 23 & 1 & \\
\hline \multicolumn{4}{|l|}{ Clinical stage } & \multirow{3}{*}{0.165} \\
\hline Tis-T1 & 32 & 23 & 9 & \\
\hline $\mathrm{T} 2-\mathrm{T} 4$ & 46 & 39 & 7 & \\
\hline
\end{tabular}

Table 3. Correlations between filter-tipped cigarette smoking and WWOX expression level in bladder cancer patients

\begin{tabular}{lcccc}
\hline \multirow{2}{*}{ Groups } & \multirow{2}{*}{ Samples (n) } & \multicolumn{2}{c}{ WWOX protein } & \multirow{2}{*}{ P value } \\
\cline { 3 - 4 } & & High & Low & \\
\hline Cigarette status & 29 & 3 & 26 & \\
Never & 16 & 3 & 13 & \\
Former & 33 & 10 & 23 & \\
Current & & & & $P=0.149$ \\
Extent of smoking & 21 & 3 & 18 & \\
Heavy & 20 & 5 & 15 & \\
Moderate & 8 & 5 & 3 & \\
Light & & & & \\
\hline
\end{tabular}

Abbreviation: WWOX, WW domain containing oxidoreductase 
kinetics as that of the promoter (Figure 2E and F). More importantly, the hypermethylation was specifically induced by CSE with a kinetics concurrent to the suppression of WWOX mRNA, suggesting that CSE treatment could inhibit the expression of WWOX through the induction of the CpG islands nearby transcription start site from unmethylated to heavy methylated in T-24 cells.

Elevated expression of DNMT1 was induced by CSE in T-24 cells. Altered expressions of DNMTs have been associated with the aberrant hypermethylation of tumor suppressor genes in cancers $(25,26)$. In order to determine which DNMT participates in the CSE-induced hypermethylation of WWOX, we examined the mRNA levels of DNMT1, DNMT3A and DNMT3B in T-24 cells treated with CSE for 1-3 days. As shown in Figure 3A, quantitative Real-Time RT-PCR revealed a time-dependent induction of DNMT1 and this result was further corroborated with western blot analysis (Figure 3B). However, we did not find significant mRNA alterations of DNMT3A or DNMT3B in CSE treated cells (data not shown). Taken together, these results suggest that the elevated expression of DNMT1, but not DNMT3A or DNMT3B was involved in the CSE-induced hypermethylation of WWOX gene.

\section{Discussion}

In the current study, we examined the WWOX protein expression in 78 BTCC tissues and 26 normal bladder tissues by using immunohistochemistry. Loss of WWOX protein expression was observed in the majority of BTCC tissues, but rarely found in normal bladder tissues. Furthermore, WWOX expression was correlated with tumor grade $(P=0.019)$ and cigarette smoking $(P=0.031)$. Considering the fact that methylation of $\mathrm{CpG}$ islands plays an important role in the inactivation of WWOX, we were interested in whether similar mechanism of WWOX also occurs in bladder cancer cells. Therefore, we treated bladder cancer cells T-24 with CSE and further examined the expression level of WWOX as well as the methylation status of CpG islands within the WWOX promoter and exon 1. We found that hypermethylation of WWOX promoter and exon 1 was specifically induced by CSE with a kinetics concurrent to the suppression of WWOX mRNA in bladder cancer cells. In addition, CSE treatment induced a significant time-dependent increase in the level of DNMT1, but has no effects on DNMT3A and DNMT3B.

WWOX expression was absent or reduced in $79.5 \%$ (62/78) of our series of BTCC. This was consistent with previous studies in other cancer types (27-29). This evidence suggests that loss of WWOX expression should be involved in a wide range of human cancers. However, a recent study from Ramos D et al reported that only 55.5\% urothelial bladder cancer showed a reduced level of WWOX protein expression, which was lower than that of our study (30). This discrepancy may depend on the score system and antibodies used. However, in agreement with our study, they also found that WWOX expression was significantly associated with tumor grade, suggesting that WWOX could play a significant role in bladder cancer progression. Notably, the current study also revealed that the reduced expression of WWOX in BTCC was associated with cigarette use, especially current cigarette smoking and heavy cigarette consumption. The evidence indicated that cigarette smoking may be a risk factor related to the reduced or altered expression of WWOX in bladder cancers.

Accumulating evidence has demonstrated that cigarette smoking could induce epigenetic changes through promoter methylation of tumor suppressor genes and methylation of $\mathrm{CpG}$ islands plays a crucial role in the inactivation of WWOX in various cancers (31-33). These findings lead us to explore whether cigarette smoking could induce hypermethylation of WWOX, thereby inhibiting the expression of WWOX in bladder cancer cells. In the present study, we found that CSE treatment consistently caused the inactivation of WWOX and hypermethylation of $\mathrm{CpG}$ islands with WWOX promoter and exon 1. However, since CSE treatment induced a rapid methylation of both $\mathrm{CpG}$ islands nearby the transcription start site of WWOX gene, we failed to identify which CpG island is more important in the regulation of WWOX. According to the observations from Iliopoulos et al., sparse methylation in WWOX exon 1 in nonneoplastic lung tissue adjacent to cancer may be an early marker of carcinogen exposure (24). We assumed that the CpG island within WWOX exon 1 is the preferred methylated region of cigarette exposure, whereas the methylation of WWOX promoter seems to play a vital role in the inactivation of WWOX. DNMTs are known to be essential for the generation of genomic methylation patterns, which leads to transcriptional silencing. DNMT1, responsible for both de novo and maintenance methylation of tumor suppressor genes, was specifically upregulated by CSE treatment with kinetics concurrent to both WWOX methylation and inactivation, suggesting that DNMT1 was involved in the CSE-induced hypermethylation of WWOX gene $(34,35)$. Some previous reports described difficulties in detection of DNMT3A and DNMT3B by Western blot using available commercial antibodies, quantitative Real-Time RT-PCR for DNMT3A and DNMT3B was performed instead, but no significant changes of DNMT3A and DNMT3B were observed in CSE-treated cells (36). Nonetheless, our work could not exclude the cooperative roles of DNMT3A or DNMT3B, and the precise mechanisms of DNMTs in the CSE-induced methylation process need to be further elucidated in welldesigned experiments.

In summary, our study demonstrated that loss of WWOX protein expression occurs in the majority of our examined BTCC tissues and is correlated with tumor grade and cigarette smoking, suggesting that WWOX could be involved quite frequently in bladder tumorigenesis. Moreover, hypermethylation of WWOX induced by cigarette smoking may represent one underlying mechanism for the loss expression of WWOX in bladder cancer. 


\section{References}

[1] JEMAL A, BRAY F, CENTER MM, FERLAY J, WARD E et al. Global cancer statistics. CA Cancer J Clin 2011; 61: 69-90. http://dx.doi.org/10.3322/caac.20107

[2] BRYAN RT, HUSSAIN SA, JAMES ND, JANKOWSKI JAWALLACE DM. Molecular pathways in bladder cancer: part 1. BJU Int 2005; 95: 485-490.

[3] HIRAO Y, KIM WJFUJIMOTO K. Environmental factors promoting bladder cancer. Curr Opin Urol 2009; 19: 494-499. http://dx.doi.org/10.1097/MOU.0b013e32832eb4ef

[4] VINEIS P, KOGEVINAS M, SIMONATO L, BRENNAN PBOFFETTA P. Levelling-off of the risk of lung and bladder cancer in heavy smokers: an analysis based on multicentric case-control studies and a metabolic interpretation. Mutat Res 2000; 463: 103-110.

[5] VINEIS P, MARINELLI D, AUTRUP H, BROCKMOLLER J, CASCORBI I et al. Current smoking, occupation, Nacetyltransferase- 2 and bladder cancer: a pooled analysis of genotype-based studies. Cancer Epidemiol Biomarkers Prev 2001; 10: 1249-1252.

[6] CHEN T, SAHIN AALDAZ CM. Deletion map of chromosome $16 \mathrm{q}$ in ductal carcinoma in situ of the breast: refining a putative tumor suppressor gene region. Cancer Res 1996; 56: 5605-5609.

[7] LATIL A, CUSSENOT O, FOURNIER G, DRIOUCH KLIDEREAU R. Loss of heterozygosity at chromosome $16 \mathrm{q}$ in prostate adenocarcinoma: identification of three independent regions. Cancer Res 1997; 57: 1058-1062.

[8] YUS, MANGELSDORF M, HEWETT D, HOBSON L, BAKER $\mathrm{E}$ et al. Human chromosomal fragile site FRA16B is an amplified AT-rich minisatellite repeat. Cell 1997; 88: 367-374. http://dx.doi.org/10.1016/S0092-8674(00)81875-9

[9] DENNIS TRSTOCK AD. A molecular cytogenetic study of chromosome 3 rearrangements in small cell lung cancer: consistent involvement of chromosome band 3q13.2. Cancer Genet Cytogenet 1999; 113: 134-140. http://dx.doi. org/10.1016/S0165-4608(99)00023-0

[10] BARNES LD, GARRISON PN, SIPRASHVILI Z, GURANOWSKI A, ROBINSON AK et al. Fhit, a putative tumor suppressor in humans, is a dinucleoside 5,5“'-P1,P3-triphosphate hydrolase. Biochemistry 1996; 35: 11529-11535.

[11] BEDNAREK AK, LAFLIN KJ, DANIEL RL, LIAO Q, HAWKINS KA et al. WWOX, a novel WW domain-containing protein mapping to human chromosome 16q23.3-24.1, a region frequently affected in breast cancer. Cancer Res 2000; 60: 2140-2145.

[12] DEL MARE S, SALAH ZAQEILAN RI. WWOX: its genomics, partners, and functions. J Cell Biochem 2009; 108: 737-745. http://dx.doi.org/10.1002/jcb.22298

[13] PICHIORRI F, ISHII H, OKUMURA H, TRAPASSO F, WANG $\mathrm{Y}$ et al. Molecular parameters of genome instability: roles of fragile genes at common fragile sites. J Cell Biochem 2008; 104: 1525-1533. http://dx.doi.org/10.1002/jcb.21560

[14] O'KEEFE LVRICHARDS RI. Common chromosomal fragile sites and cancer: focus on FRA16D. Cancer Lett 2006; 232: 37-47. http://dx.doi.org/10.1016/j.canlet.2005.07.041
[15] LAI FJ, CHENG CL, CHEN ST, WU CH, HSU LJ et al. WOX1 is essential for UVB irradiation-induced apoptosis and down-regulated via translational blockade in UVB-induced cutaneous squamous cell carcinoma in vivo. Clin Cancer Res 2005; 11: 5769-5777. http://dx.doi.org/10.1158/1078-0432. CCR-04-2274

[16] SOZZI G, SARD L, DE GREGORIO L, MARCHETTI A, MUSSO K et al. Association between cigarette smoking and FHIT gene alterations in lung cancer. Cancer Res 1997; 57: 2121-2123.

[17] FUJIWARA K, FUJIMOTO N, TABATA M, NISHII K, MATSUO K et al. Identification of epigenetic aberrant promoter methylation in serum DNA is useful for early detection of lung cancer. Clin Cancer Res 2005; 11: 1219-1225.

[18] LIN RK, HSIEH YS, LIN P, HSU HS, CHEN CY et al. The tobacco-specific carcinogen NNK induces DNA methyltransferase 1 accumulation and tumor suppressor gene hypermethylation in mice and lung cancer patients. J Clin Invest 2010; 120: 521-532. http://dx.doi.org/10.1172/ LCI40706

[19] LEE SM, LEE JY, CHOI JE, LEE SY, PARK JY et al. Epigenetic inactivation of retinoid $\mathrm{X}$ receptor genes in non-small cell lung cancer and the relationship with clinicopathologic features. Cancer Genet Cytogenet 2010; 197: 39-45. http://dx.doi. org/10.1016/j.cancergencyto.2009.10.008

[20] LIU Q, WANG M, GUO J, LI J, LI C et al. Effect of socioeconomic status on secondary prevention of stroke. Int J Qual Health Care 2011; 23: 405-412. http://dx.doi.org/10.1093/intqhc/mzr021

[21] TAMAKOSHI A, YUZAWA M, MATSUI M, UYAMA M, FUJIWARA NK et al. Smoking and neovascular form of age related macular degeneration in late middle aged males: findings from a case-control study in Japan. Research Committee on Chorioretinal Degenerations. Br J Ophthalmol 1997; 81: 901-904. http://dx.doi.org/10.1136/bjo.81.10.901

[22] GULER G, UNER A, GULER N, HAN SY, ILIOPOULOS $\mathrm{D}$ et al. Concordant loss of fragile gene expression early in breast cancer development. Pathol Int 2005; 55: 471-478. http://dx.doi.org/10.1111/j.1440-1827.2005.01855.x

[23] OLTMANNS U, CHUNG KF, WALTERS M, JOHN MMITCHELL JA. Cigarette smoke induces IL-8, but inhibits eotaxin and RANTES release from airway smooth muscle. Respir Res 2005; 6: 74. http://dx.doi.org/10.1186/1465-9921$\underline{6-74}$

[24] ILIOPOUlOS D, GULER G, HAN SY, JOHNSTON D, DRUCK T et al. Fragile genes as biomarkers: epigenetic control of WWOX and FHIT in lung, breast and bladder cancer. Oncogene 2005; 24: 1625-1633. http://dx.doi.org/10.1038/ sj.onc. 1208398

[25] PRUITT K, ULKU AS, FRANTZ K, ROJAS RJ, MUNIZMEDINA VM et al. Ras-mediated loss of the pro-apoptotic response protein Par- 4 is mediated by DNA hypermethylation through Raf-independent and Raf-dependent signaling cascades in epithelial cells. J Biol Chem 2005; 280: 23363-23370. http://dx.doi.org/10.1074/jbc.M503083200

[26] OKA M, RODIC N, GRADDY J, CHANG LJTERADA N. CpG sites preferentially methylated by Dnmt3a in vivo. J Biol 
Chem 2006; 281: 9901-9908. http://dx.doi.org/10.1074/jbc. M511100200

[27] AQEILAN RI, KUROKI T, PEKARSKY Y, ALBAGHA O, TRAPASSO $\mathrm{F}$ et al. Loss of WWOX expression in gastric carcinoma. Clin Cancer Res 2004; 10: 3053-3058. http://dx.doi. org/10.1158/1078-0432.CCR-03-0594

[28] DONATI V, FONTANINI G, DELL'OMODARME M, PRATI MC, NUTI S et al. WWOX expression in different histologic types and subtypes of non-small cell lung cancer. Clin Cancer Res 2007; 13: 884-891. http://dx.doi.org/10.1158/1078-0432. CCR-06-2016

[29] WANG M, GU J, WANG YGONG B. Loss of WWOX expression in human extrahepatic cholangiocarcinoma. J Cancer Res Clin Oncol 2009; 135: 39-44. http://dx.doi.org/10.1007/ $\underline{\text { s00432-008-0449-4 }}$

[30] RAMOS D, ABBA M, LOPEZ-GUERRERO JA, RUBIO J, SOLSONA E et al. Low levels of WWOX protein immunoexpression correlate with tumour grade and a less favourable outcome in patients with urinary bladder tumours. Histopathology 2008; 52: 831-839. http://dx.doi.org/10.1111/ j.1365-2559.2008.03033.x

[31] LEWANDOWSKA U,ZELAZOWSKI M, SETA K, BYCZEWSKA M, PLUCIENNIK E et al. WWOX, the tumour suppressor gene affected in multiple cancers. J Physiol Pharmacol 2009; 60 Suppl 1: 47-56.

[32] NAKAYAMA S, SEMBA S, MAEDA N, MATSUSHITA M, KURODA Y et al. Hypermethylation-mediated reduction of WWOX expression in intraductal papillary mucinous neoplasms of the pancreas. Br J Cancer 2009; 100: 1438-1443. http://dx.doi.org/10.1038/sj.bjc.6604986

[33] WANG X, CHAO L, JIN G, MA G, ZANG Y et al. Association between $\mathrm{CpG}$ island methylation of the WWOX gene and its expression in breast cancers. Tumour Biol 2009; 30: 8-14. http://dx.doi.org/10.1159/000197911

[34] JAIR KW, BACHMAN KE, SUZUKI H, TING AH, RHEE I et al. De novo CpG island methylation in human cancer cells. Cancer Res 2006; 66: 682-692. http://dx.doi.org/10.1158/00085472.CAN-05-1980

[35] TING AH, JAIR KW, SCHUEBEL KEBAYLIN SB. Differential requirement for DNA methyltransferase 1 in maintaining human cancer cell gene promoter hypermethylation. Cancer Res 2006; 66: 729-735. http://dx.doi.org/10.1158/0008-5472. CAN-05-1537

[36] HSIEH CL. In vivo activity of murine de novo methyltransferases, Dnmt3a and Dnmt3b. Mol Cell Biol 1999; 19: 8211-8218. 